\title{
P I I-I0. Modulation of intestinal T cells following infection of macaques with live attenuated and conditionally replication-competent SIV
}

\author{
MS Manoussaka*1, R Stebbings ${ }^{2}$, R Quartey-Papafio², M Robinson², M Page ${ }^{2}$, \\ AT Das $^{3}$, W Kleibeuker ${ }^{3}$, B Klaver ${ }^{3}$, B Berkhout ${ }^{3}$, N Almond $^{2}$ and M Cranage ${ }^{1}$
}

Address: ${ }^{1}$ Cellular and Molecular Medicine, St George's University, London, UK, ${ }^{2}$ National Institute of Biological Standards, Health Protection Agency, Potters Bar, UK and ${ }^{3}$ Academic Medical Centre of the University of Amsterdam, Amsterdam, Netherlands

* Corresponding author

from AIDS Vaccine 2009

Paris, France. 19-22 October 2009

Published: 22 October 2009

Retrovirology 2009, 6(Suppl 3):PI55 doi:10.1 186/1742-4690-6-S3-PI55

This abstract is available from: http://www.retrovirology.com/content/6/S3/PI55

(c) 2009 Manoussaka et al; licensee BioMed Central Ltd.

\section{Background}

Live-attenuated SIV can induce superinfection resistance; however, the mechanism of this effect is not understood and may have implications for HIV vaccine development. To further investigate the role of virus replication in conferring protection we have analysed $\mathrm{T}$ cell phenotype and responses in gut tissue following infection of macaques with either SIVmac239 $\Delta$ nef or a doxycycline-dependent replication variant of SIVmac239 $\Delta$ nef designated SIVrtTA.

\section{Methods}

Mononuclear cells (MNC) were recovered from small and large intestine of four rhesus macaques infected with SIVrtTA for 26 weeks in the presence of orally-administered doxycycline. In two animals doxycycline was withdrawn for 8 weeks before analysis (Group A) and in 2 macaques analysis was performed at week 26 (Group B). A further two animals were analysed after 26 weeks of infection with SIVmac2394nef (Group C). Peripheral blood mononuclear cells (PBMC) were recovered at the same time points. Polychromatic flow cytometry was used to assess the percentages of central memory $\left(\mathrm{T}_{\mathrm{cm}}\right)$ $\left(\mathrm{CD} 28^{+} \mathrm{CD}^{+} 5^{+}\right)$and effector memory $\left(\mathrm{T}_{\mathrm{em}}\right)\left(\mathrm{CD} 28^{-}\right.$ CD95 ${ }^{+}$) $\mathrm{T}$ cells as well as CD4 and CD8 T responses to SIV Gag, Rev and Tat by the detection of TNF- $\alpha$ and IL-2.

\section{Results}

In animals with actively replicating SIV (Groups B \& C) the percentage of CD4 and CD8 $\mathrm{T}_{\mathrm{cm}}$ both in peripheral blood, and to a lesser extent, in the small and large intestine were relatively low compared to CD4 and CD8 $\mathrm{T}_{\mathrm{em}}$. In contrast, the reverse pattern was seen in animals where SIV replication was turned off by withdrawal of doxycycline (Group A). Intestinal MNC responded to Gag peptides producing TNF- $\alpha$ and IL-2. Animals withdrawn from doxycycline had Rev and Tat-specific $\mathrm{CD}^{+}$and $\mathrm{CD}^{+}$ TNF- $\alpha$ producing $\mathrm{T}$ cells in both small and large intestine.

\section{Conclusion}

SIVrtTA offers a system for dissecting the parameters of replication, immune response and protective efficacy to more fully understand in vivo superinfection resistance. 